Article

\title{
Fabrication of color glass with high light transmittance by pearlescent pigment and optical adhesive
}

\author{
Hyeon-Sik Ahn'1, Akpeko Gasonoo ${ }^{2}$, Seong-Min Lim¹, Jae-Hyun Lee ${ }^{3}$, and Yoonseuk Choi ${ }^{1, *}$
}

1 Department of Electronic Engineering, Hanbat National University, Daejeon 34158, Republic of Korea; princass123@naver.com (H.-S.A.); seongmin625@naver.com (S.-M.L.)

2 Research Institute of Printed Electronics \& 3D Printing, Hanbat National University, Daejeon 34158, Republic of Korea; amoebatheo2009@gmail.com

3 Department of Creative Convergence Engineering, Hanbat National University, Daejeon 34158, Republic of Korea; jhyunlee@hanbat.ac.kr

* Correspondence: ychoi@hanbat.ac.kr; +82-42-821-1134

\begin{abstract}
In this study, we propose a solution process for realizing color glass for building integrated photovoltaic (BIPV) systems by spin coating a color solution composed of a pearlescent pigment mixed in a norland optical adhesive (NOA) matrix. Color solutions are made from mixing pearlescent pigments in NOA63. Compared to a physical vapor deposition process, color coatings are achieved by spin coating in a relatively simple and inexpensive process at room temperature. The optical properties can be easily controlled by adjusting the spin coating speed and the concentration of the pearlescent pigments. The produced color glasses achieved a high transmittance of $85 \%$ or more in the visible wavelength range, except the wavelength spectrum exhibiting the maximum reflectance. In addition, we propose a one-step lamination process of color glass on a solar cell by leveraging on the adhesive property of the NOA matrix. This eliminates the cost and process of additional ethylene vinyl acetate (EVA) layer or other materials used in the conventional lamination process. The color glass produced through this study has stability that does not change its properties over time. Therefore, it is expected to be applied to the BIPV solar module market where aesthetics and energy efficiency are required.
\end{abstract}

Keywords: BIPV; pearlescent pigment; NOA; spin coating; high transmittance; lamination process

\section{Introduction}

Recently, the efficient production and consumption of eco-friendly renewable energy has become an important research subject due to climate change. From the architectural design point of view, research on a system that generates electricity using solar energy and can be integrated into the exterior wall of a building, is of high interest and has been actively investigated [1-4]. A novel approach of building integrated photovoltaic (BIPV) system on the outer wall of the building has been developed, and many architectural structures based on this have been proposed $[5,6]$. The BIPV system which comprises solar cells, is mainly installed on the roof of a building or on the outer wall of a building, which has a relatively large area to efficiently produce solar energy in buildings. The building to which the BIPV system is applied is eco-friendly and can be self-sufficient or energy-saving, making it economical and very efficient $[7,8]$. Through the large-scale application and integration of solar energy technology, it becomes possible to generate energy in every kind of building. A significant portion of the generated electricity is consumed within the built environment, and the power distribution and transportation costs by the smart grid is significantly reduced [8]. To apply the BIPV system, various factors such as the efficiency of the solar panel, the transmittance of the front color glass, the insulation and 
antifouling function of the panel, the structure that can increase the efficiency of solar energy, and many others must be considered [9].

With the advancement of solar panel technology such as organic photovoltaic, highefficiency and high-performance panels have been developed [10-14]. However, conventional solar panels are usually black or blue, which is not preferred by most users. In buildings where aesthetics is important, front color glasses with high light transmittance that can withstand the harsh environmental conditions are required. To minimize the decrease in the efficiency of solar power generation while securing aesthetics, various studies on front color glasses have been reported [15-19]. Color glass maximizes reflection at a desired wavelength and shows a variety of colors when viewed externally, thereby concealing the solar panel while ensuring aesthetics and limited reflection to a specific wavelength are promoted. Since it has high transmittance to other wavelengths except for the reflected spectra, it minimizes the decrease in the efficiency of the solar panel.

Kromatix technology [19] applied a multilayer coating on the inner glass surface by evaporation in a low-pressure plasma process. Low-pressure plasma process such as atomic layer deposition has great potential to produce thin, uniform, and conformal films with accurate thickness while minimizing substrate damage. Unfortunately, most of the materials chosen for the multilayer structures have a low refractive index. As a result, thick layers to get bright and desired colors are required. This method is expensive, has a long deposition time, produces low transmittance layers and is not applicable to commercial BIPV systems. Recently, we implemented color glass for BIPV through multilayer deposition of alternating high and low refractive index metal oxides and metal nitrides [20-22]. Some of these oxide and nitride layers have been used in thin-film optical applications because of their high transmittance and stable optical properties [23]. However, for large area application, deposition of high refractive index materials such as metal oxides and metal nitrides is sensitive to thickness, making it difficult to exhibit uniform properties in one film. Also, the color changes easily depending on the viewing angle. Therefore, it is not suitable for implementing uniform, stable and large area color glasses. Recently, various studies are investigating a method of developing color glass through a polymer-based solution process instead of vapor deposition [24]. This can resolve the problem of non-uniformity in large area application and many other challenges which are mostly associated with the physical vapor deposition processes. Moreover, the marketability of most conventional color glasses is difficult due to the high material price and the need for a lamination process using ethylene vinyl acetate (EVA). Therefore, there is a need to develop economical color glass that can secure aesthetic elements of buildings while having high transmittance that can be applied to BIPV systems.

In this paper, a manufacturing process of color glass is proposed by depositing pearlescent pigments through a solution process technique. Pearlescent pigments are composed of plate-shaped crystals unlike general pigments [25]. The reflected light is generated through the interference of light caused by the difference in the refractive index of the plate-shaped crystal and that of the pigments, resulting in appealing colors like natural pearls or metallic lusters. These are special pigments due to their optical effect [25]. Analysis of the optical properties of the color films are made through the measurement of transmittance and reflectance. In the lamination process of the manufactured front color glass onto the solar panel, the process time and cost can be reduced by omitting the EVA film lamination used in the existing processes by rather leveraging on the adhesive properties of the NOA. The spin-coated color films are directly laminated on the solar cells by UV curing in a one-step process. Finally, the effect of the color glass on the solar power generation efficiency and stability of the BIPV module are analyzed. It is demonstrated that more than $94 \%$ of solar efficiency can be achieved for PV cells laminated with the color glasses. Through the development of this technology, it is expected that color glasses with free color choice will be possible in the future, and it will be applied to low-cost BIPV systems with improved aesthetics and energy efficiency. 


\section{Materials and Methods}

\subsection{Fabrication of Color Glass using Pearlescent Pigments}

In this section, we present the manufacturing process of color glass by pearlescent pigments in a solution process and propose a one-step UV curing to laminate the color glasses on solar cells. The pearlescent pigments used for preparing the color solutions are A-781K (Splendor Blue), AX-701K (Dazzling Gold), AX-741 (Dazzling Red), AX-761 (Dazzling Violet), AX-791K (Dazzling Green) and AX-901K (Dazzling Standard). All the pearlescent pigments were supplied by CQV (Korea). The particle size of the pearlescent pigments ranges from 5 41 um and were uniformly mixed in NOA63 matrix (Norland Products, USA) (Fig. S1). The glass substrates $\left(2.5 \times 2.5 \mathrm{~cm}^{2}\right)$ used in this study were mist type and normal type (NURI CORP, Korea). The mist glass creates a scattering effect on the back side to show a distinct color by the scattered light. The two types of glass substrates were cleaned with de-ionized water and acetone for 15 minutes each in an ultrasonic bath, boiled for 15 minutes with isopropyl alcohol (IPA), and dried in an oven at 150 ${ }^{\circ} \mathrm{C}$ for 15 minutes. The solution was prepared with $5 \mathrm{wt} . \%$ of pearlescent pigment in NOA63. A color layer was formed on a glass substrate by using a spin coating method with a color solution. The color glass fabrication process is shown in Figure 1. The glass substrate was placed on a spin coater and the prepared color solution was applied. Spin coating was done at $500 \mathrm{rpm}$ for 5 seconds to evenly disperse the applied solution. Next, the spin coating speed was increased between $1000 \mathrm{rpm}$ and $3000 \mathrm{rpm}$ for 50 seconds to tune the thickness of each color film. Lastly, the color glass was cured in 15 minutes by an ultraviolet (UV) with a wavelength of $365 \mathrm{~nm}$. The thickness of the color films was measured by alpha step measurement (Dektak 150, Veeko, Hong Kong) while the optical transmittance and reflectance were measured with an ultraviolet visible light near-infrared spectrophotometer (Lambda 950 UV-vis-NIR, PerkinElmer).

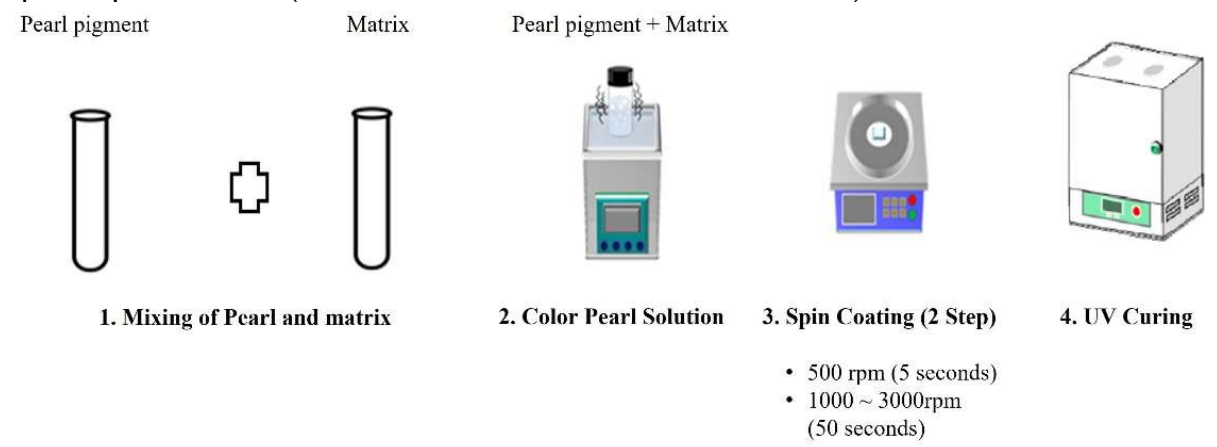

Figure 1. Color glass fabrication process (pre-coating the prepared color solution at $500 \mathrm{rpm}$ for 5 seconds, then spin coating at 1000 or $3000 \mathrm{rpm}$ ).

\subsection{Lamination process of color glass on Solar Cell}

After spin coating the color solution on the glass substrate, it is directly attached to the solar panel to perform the lamination process. Figure 2 shows the components of the conventional and proposed solar cell with laminated color glasses, respectively. As shown in Fig. 2(a), the conventional system employs EVA as the laminating film. However, as shown in Fig. 2(b), the proposed NOA63 based color solution is spin coated on the glass substrate and directly laminated to the solar cell. In addition, NOA63 is coated on the back sheet and laminated at the rear side of the solar panel. In the proposed system, the entire structure is cured using UV having a power of $0.61 \mathrm{~mW} / \mathrm{cm}^{2}$ at $365 \mathrm{~nm}$. The use of EVA in the conventional lamination is eliminated completely, thereby reducing the process time and cost significantly. The color glass for the solar cell test was fabricated on $9 \times 4 \mathrm{~cm}^{2}$ normal glass at a spin coating speed of $1500 \mathrm{rpm}$, and the power generation efficiency was measured using a solar cell efficiency measuring device (McScience, K201LAB50). 
(a)

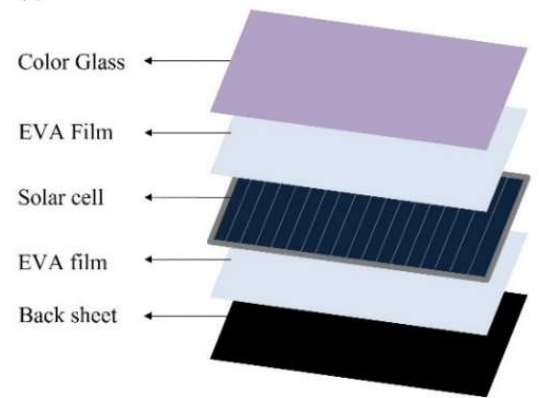

(b)

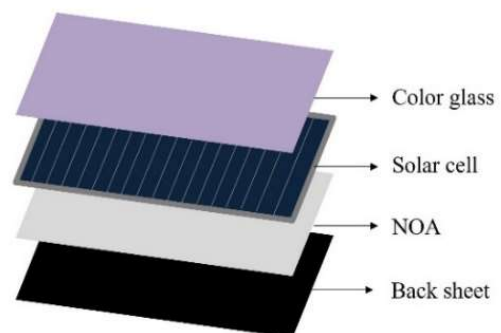

Figure 2. Solar cell lamination process for BIPV system (a) Existing process using EVA film (b) Proposed lamination process without EVA film.

\section{Results and Discussion}

\subsection{Thickness of color films and the optical characteristics of the colorglasses}

The thickness of the thin film prepared by spin coating was investigated. Table 1 shows the structure of the color glass samples A, B, C, D, E, and F. Generally, each sample structure is of the order: glass/color film, where the color of each film is indicated in the third column, respectively.

Table 1. Structure of the fabricated color glasses.

\begin{tabular}{ccc}
\hline Sample & Layer Structure & Color \\
\hline A & Glass / A-781K + NOA63 & Splendor Blue \\
B & Glass / AX-701K + NOA63 & Dazzling Gold \\
C & Glass / AX-741K + NOA63 & Dazzling Red \\
D & Glass / AX-761K + NOA63 & Dazzling Violet \\
E & Glass / AX-791K + NOA63 & Dazzling Green \\
F & Glass / AX-901K + NOA63 & Dazzling Standard \\
\hline
\end{tabular}

Figure 3 shows the thickness of the films deposited at $1000 \mathrm{rpm}$ and $3000 \mathrm{rpm}$, respectively. Samples spin-coated at $1000 \mathrm{rpm}$ and $3000 \mathrm{rpm}$ resulted in color layers with thickness in the range of 63 70 um and 21 23 um, respectively. Thus, it is demonstrated that thin films of 21 70 um can be deposited by simply adjusting the spin coating speed in the range of 1000 to $3000 \mathrm{rpm}$. The thickness of the thin film is an important factor in controlling the reflectance and transmittance of the color glass. Therefore, the reflectance and transmittance can be freely controlled by adjusting the spin coating speed.

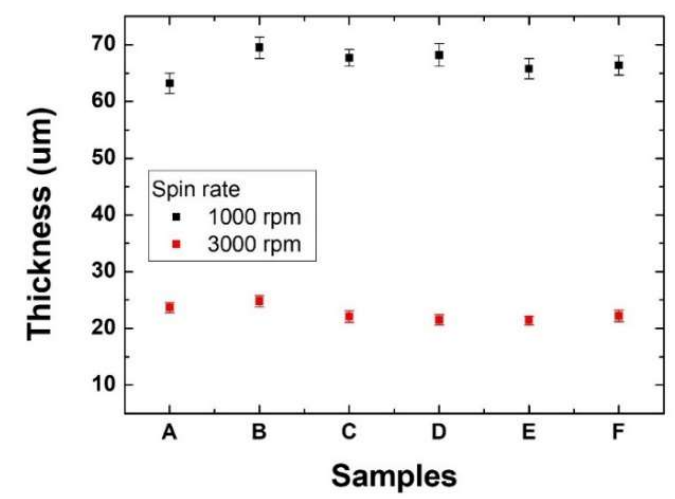

Figure 3. The thickness of the thin film formed according to the spin coating speed of $1000 \mathrm{rpm}$ (Black, square), and $3000 \mathrm{rpm}$ (red, square), respectively. 
The optical characteristics of the color glasses was investigated. First, the effect of the glass substrates on the reflectance and transmittance spectra is analyzed. Figure 4 shows the reflectance and transmittance spectra of blue and green color films spin coated at 1000 rpm on normal and mist glass substrates, respectively. The mist glass has the same thickness and refractive index of 1.52 as the normal glass. However, it causes a scattering effect with little effect on the transmittance and reflectance spectra. The optical properties are determined by the optical path difference (OPD) [26].

$$
O P D=2 \times n \times d \times \cos \theta
$$

where $\theta$ is the angle of incidence, $n$ is the refractive index, and $d$ is the thickness of the color film. For the same angles of incidence, the resultant OPD in both glass types are the same, yielding similar optical properties. Thus, it is demonstrated that similar transmittance, and color brightness are achieved in both glass types, regardless of the color of the pearlescent pigment. However, due to the scattering effect, mist glass with the color film effectively hides the solar panel while maintaining the efficiency and color brightness.

(a)

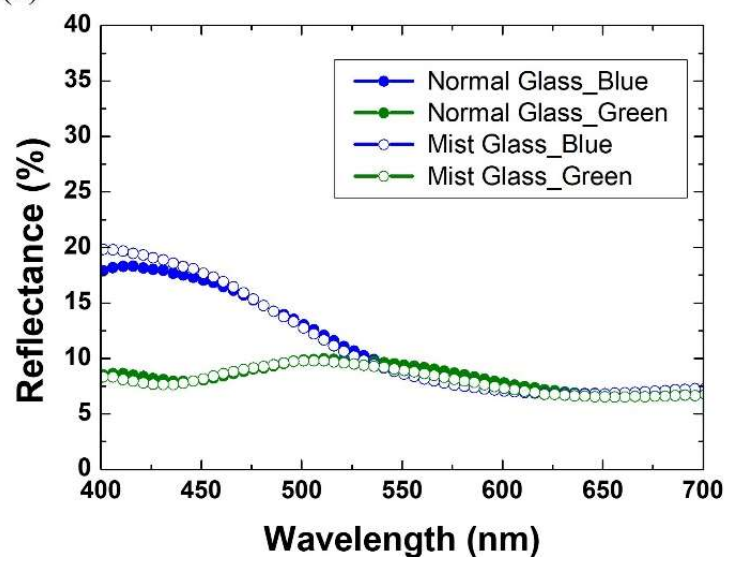

(b)

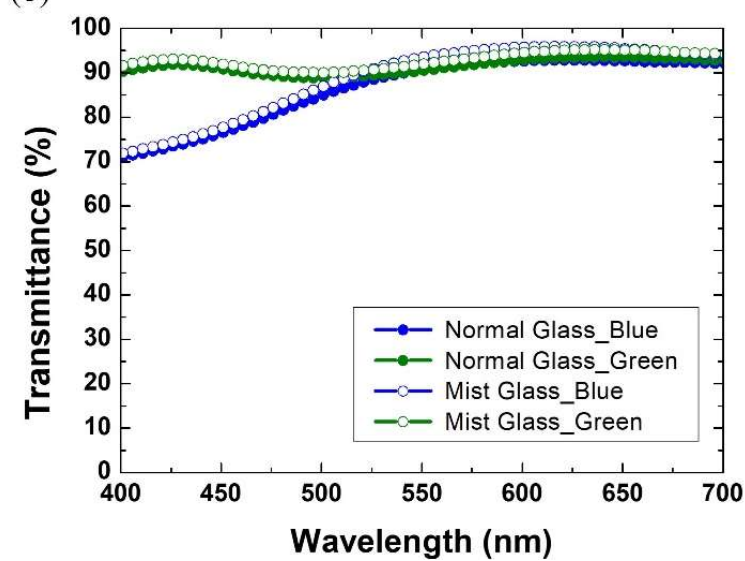

Figure 4. (a) Reflectance and (b) transmittance spectra of color films spin coated at $1000 \mathrm{rpm}$ on normal and mist glass substrates, respectively. Blue color solutions were deposited on normal glass (blue, solid circle) and mist glass (blue, open circle). Green color solutions were deposited on normal glass (green, solid circle) and mist glass (green, open circle).

Next, the effect of thickness (spin coating speed) of the color films on the optical characteristics of the color glasses are investigated. Figures 5(a) and 5(b) shows the reflectance and transmittance spectra of color glass samples $A$ to $F$ prepared at a spin coating speed of $1000 \mathrm{rpm}$. The reflectance spectra in the visible range of samples A, B, C, D, E, and F, fabricated at a spin coating speed of $1000 \mathrm{rpm}$ are shown in Figure 5(a). Samples A and D achieved a maximum reflectance of about $35 \%$ and $24 \%$ for the blue and violet wavelength regions, respectively; thus, the samples exhibit blue and violet colors, respectively. Sample B shows a maximum reflectance of $25 \%$ near the wavelength range of $450 \mathrm{~nm} \sim 570 \mathrm{~nm}$. Sample C exhibits a maximum reflectance of $21 \%$ at $700 \mathrm{~nm}$ and about $19 \%$ at $400 \mathrm{~nm}$, resulting in a pale red color. Sample E exhibits evenly reflected spectra with a maximum reflectance of $21 \%$ in the wavelength range of $490 \sim 550 \mathrm{~nm}$, yielding a green color glass. Sample F exhibits even reflectance distribution over the entire visible wavelength spectrum; hence, a gray color glass is produced. Figure 5(b) shows the transmittance spectrum of the samples prepared at a spin coating speed of $1000 \mathrm{rpm}$. All samples show maximum transmittance of $85 \%$ or more for light whose wavelengths are not within the maximum reflectance range. 
(a)

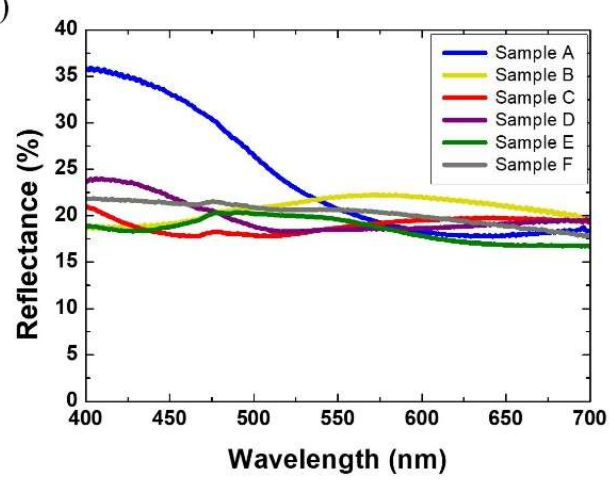

(c)

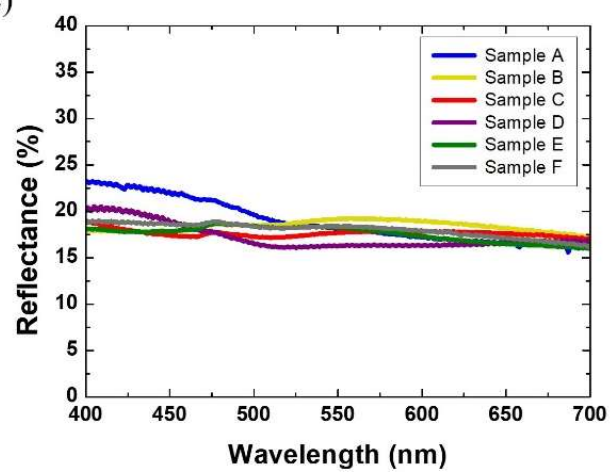

(b)

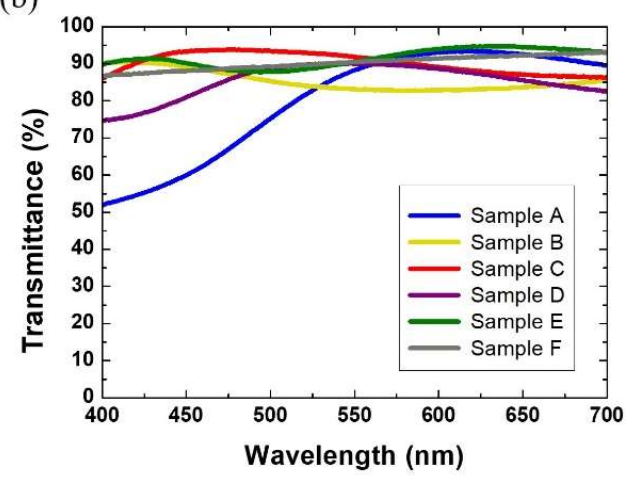

(d)

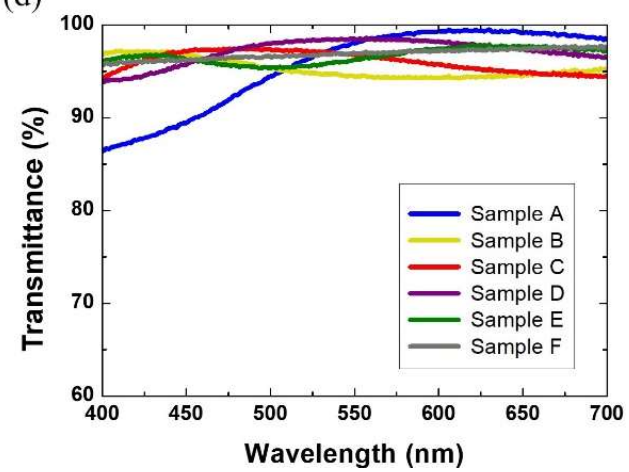

Figure 5. (a) Reflectance and (b) transmittance spectra of color glass samples produced at a spin coating speed of $1000 \mathrm{rpm}$. (c) Reflectance and (d) transmittance spectra of color glass samples produced at a spin coating speed of $3000 \mathrm{rpm}$ : A (Blue solid line), B (Yellow solid line), C (Red solid line), D (Violet solid line), E (Green solid line), F (Gray solid line).

The reflectance and transmittance spectra of samples prepared at $3000 \mathrm{rpm}$ spin coating speed are shown in Figure 5(c) and (d), respectively. Generally, it can be noticed that the samples made at a spin coating speed of $3000 \mathrm{rpm}$ have similar characteristics as samples made at a spin coating speed of $1000 \mathrm{rpm}$. However, the maximum reflectance decreased, and the maximum transmittance increased. Even though the same color is achieved but with low reflectance, the solar efficiency can be increased. The results demonstrate that the reflectance and transmittance can be easily controlled by adjusting the thickness of the color layer through the spin coating speed.

Figure 6(a) shows the actual photographs of the color glasses on a black background. It is demonstrated that uniform films are formed on the substrate without additional surface treatment. In the conventional solar module, the lamination process using EVA film is involved. The lamination process using the EVA film has disadvantages of long process time and high temperature curing requirements that are not compatible with commercial flexible applications. However, by using a NOA matrix, it is possible to laminate the color glasses in the BIPV system by adopting a solution process in a short time and at a low temperature without additional processes and materials. The color solution is spin coated on the substrate and a UV curing process conducted to laminate all elements of the module. Figure 6(b) shows the actual photographs of solar cells with the color glasses after the lamination process. Generally, each sample structure is of the order: glass/color film/PV cell.

It is demonstrated that the optical characteristics of the color glasses are not changed by the lamination process. The investigation has shown that, color glasses produced by coating pearlescent pigments mixed in NOA matrix can effectively meet both aesthetic and solar efficiency requirements. This technique also offers the advantage of a one-step 
lamination process. Therefore, it is expected to be applied to the market of developing front color glasses for BIPV systems and manufacturing cost-effective solar modules.

(a)
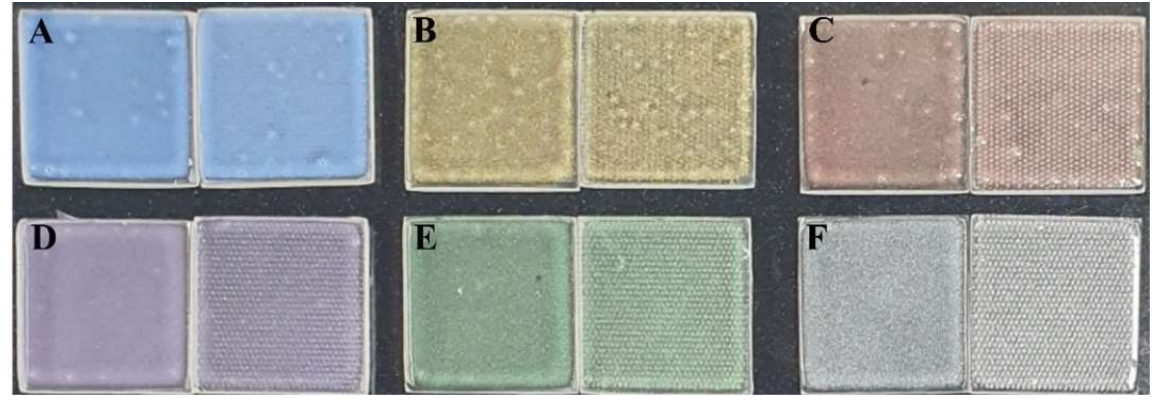

(b)
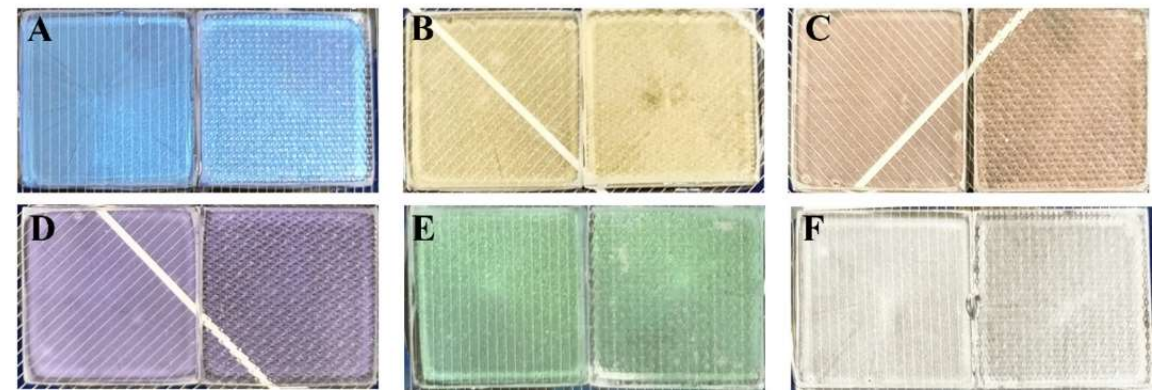

Figure 6. (a) Actual photographs of samples A to F made at a spin coating speed of $1000 \mathrm{rpm}$. (b) after lamination process of samples A to F. Left: Normal glass, right: mist glass.

\subsection{Solar efficiency of PV cells with color glass and stability analysis of the color glasses}

Large area color glass for solar efficiency measurement and stability test was fabricated on $9 \times 4 \mathrm{~cm}^{2}$ normal glass at a spin coating speed of $1500 \mathrm{rpm}$. The transmittance of these samples exhibits intermediary levels compared to the transmittance spectra of samples prepared by spin coating at $1000 \mathrm{rpm}$ and $3000 \mathrm{rpm}$, respectively (Fig. S2). The color glasses were laminated to the solar cell by a one-step lamination as previously proposed.

Figure 7(a) shows the efficiency of the PV modules with the laminated color glass samples A to F. Samples A and B show maximum transmittance of $97 \%$ and $95 \%$ at 641 and $425 \mathrm{~nm}$, respectively, and power generation efficiency of $91.07 \%$ and $89.05 \%$ compared to the reference glass. Samples C and D show the maximum transmittance of $89 \%$ and $96 \%$ at 485 and $543 \mathrm{~nm}$, respectively, and the power generation efficiency of $88.35 \%$ and $90.46 \%$ compared to the reference glass, respectively. Samples E and F showed the maximum transmittance of $94 \%$ and $92 \%$ at 440 and $700 \mathrm{~nm}$, respectively, and the power generation efficiency of $94.64 \%$ and $91.28 \%$ compared to the reference glass, respectively. It is notices that sample $\mathrm{A}$, which has the highest maximum transmittance, is not as efficient as sample E or F. Sample A has the maximum transmittance, but only in some wavelength range (570 $700 \mathrm{~nm}$ ). Compared to sample A, the maximum transmittance of Sample $\mathrm{E}$ is lower by about $3 \%$ but covers a wide wavelength range $(400 \sim 470 \mathrm{~nm}$, and $570 \sim$ $700 \mathrm{~nm}$ ) and shows the highest power generation efficiency. Sample B shows the same trend as Sample E, but the solar power generation efficiency is also low because the transmittance is lower than Sample E at wavelengths above $525 \mathrm{~nm}$. Sample C also has the lowest power generation efficiency because transmittance over the entire wavelength range is lower than that of other samples. Therefore, to increase the solar power generation efficiency, it is desirable to maintain high transmittance in a wide wavelength range, and this is also true for sample F. In addition, the photovoltaic power spectrum of a typical solar cell is made in a wide wavelength range including ultraviolet and infrared rays from 200 to $2500 \mathrm{~nm}$. Since our study is focused on the design of color glasses only for the visible wavelength range, the effect of the wavelength ranges in the ultraviolet and the infrared 
ranges have on the solar efficiency has not yet been covered. However, the ultravioletvisible-infrared spectrum can clearly affect the photovoltaic power generation.

The BIPV module must ensure the stability of the color film to external environmental conditions. Figures 7(a) and (b) show that the power generation efficiency and transmittance of color glasses were maintained for 3 months under ambient conditions, respectively, without significant degradation. It was confirmed that the degree of change in power generation efficiency according to the test period is within $0.5 \%$. This is within the margin of error. In addition, it is confirmed that the change in optical properties is insignificant. This shows that the stability of the color films made can effectively meet both the aesthetic and solar efficiency requirements. Therefore, it is expected to be applied to the development of full-color glasses for BIPV systems and the cost-effective solar module manufacturing market.

(a)

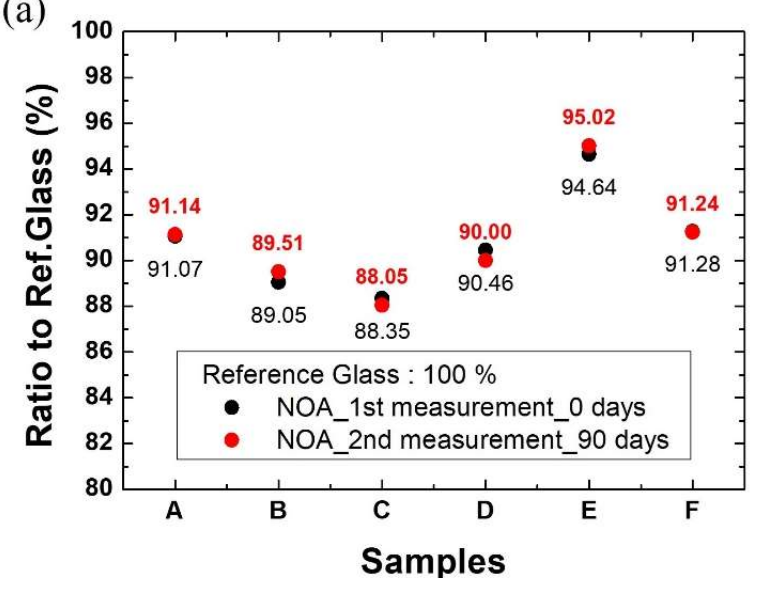

(b)

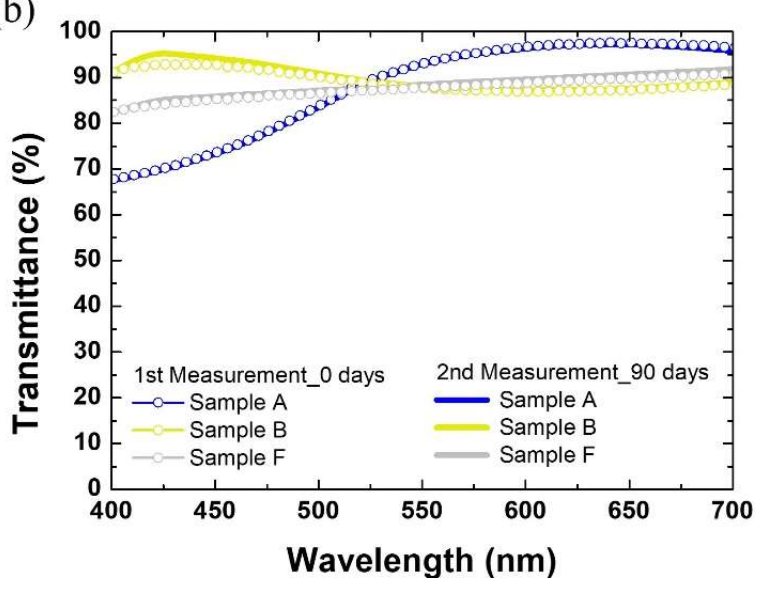

Figure 7. Characteristics and stability evaluation results of BIPV modules manufactured by colored glass A-F (a) power generation efficiency, (b) transmittance.

\section{Conclusions}

In this paper, we proposed a solution process to fabricate front color glasses for BIPV systems using a color mixture composed of pearlescent pigments and NOA63 matrix. Compared to the conventional evaporation techniques, our approach offers a simple and a cost-effective process to achieve remarkable aesthetic functional modules. The optical characteristics and thickness of the color films can be easily controlled by adjusting the spin coating speed. The fabricated color glasses achieved a high transmittance of $85 \%$ or more in the wavelength range not optimally reflected. In addition, a simple and inexpensive lamination process of the color glass on the solar panel is introduced by omitting the EVA film. The one-step lamination is achieved by conducting a UV curing of the spincoated color films directly on the solar cell. It is demonstrated that the PV with the color glass could achieve a high solar efficiency of up to $95 \%$, with an insignificant change in the color film over time. The proposed module is suitable for implementing large-area color glasses for BIPV systems by adopting printing technologies. Through the development of this technology, color glass with free color selection is expected in the future and will be applied to low-cost BIPV systems with improved aesthetics.

Supplementary Materials: The following supporting information can be downloaded at: www.mdpi.com/xxx/s1, Figure S1: Color solutions composed of pearlescent pigments and optical adhesives (NOA) matrix. From left, A-781K (Splendor Blue), AX-701K (Dazzling Gold), AX-741 (Dazzling Red), AX-761 (Dazzling Violet), AX-791K (Dazzling Green) and AX-901K (Dazzling Standard), Figure S2: transmittance spectra of color glass samples produced at a spin coating speed of $1500 \mathrm{rpm}$. 
Author Contributions: Conceptualization, Y.C., J.-H.L. and H.-S.A.; methodology, S.-M.L., A.G. and H.-S.A.; formal analysis, Y.C., J.-H.L., A.G. and H.-S.A.; investigation, Y.C., J.-H.L., A.G., H.S.A., S.-M.L.; writing-original draft preparation, H.-S.A.; writing-review and editing, A.G., Y.C. and J.-H.L.; project administration, Y.C.; funding acquisition, Y.C. All authors have read and agreed to the published version of the manuscript.

Funding: This results was supported by "Regional Innovation Strategy (RIS)" through the National Research Foundation of Korea(NRF) funded by the Ministry of Education(MOE)(2021RIS-004).

Data Availability Statement: The data presented in this study are available on request from the corresponding author.

Conflicts of Interest: The authors declare no conflict of interest.

\section{References}

1. Henemann, A. BIPV: Built-in solar energy. Renewable Energy Focus. 2008, 9, 14-19, https://doi.org/10.1016/S14710846(08)70179-3.

2. Ceron, I.; Caamano-Martin, E.; Neila, F.-J. State of the art of building integrated photovoltaic products. Renewable Energy 2013, 58, 127-133, https://doi.org/10.1016/j.renene.2013.02.013.

3. Shukla, A.-K.; Sudhakar, K.; Baredar, P. Recent advancement in BIPV product technologies: A review. Energy and Buildings. 2017, 140, 188-195, https://doi.org/10.1016/j.enbuild.2017.02.015.

4. Enkvist, P.-A.; Dinkel, J.; Lin, C. Impact of the Financial Crisis on Carbon Economics: Version 2.1 of the Global Greenhouse Gas Abatement Cost Curve. McKinsey \& Company 2010.

5. Tombazis, A.-N. Architectural design: A multifaceted approach. Renewable energy. 1994, 5, 893-899, https://doi.org/10.1016/0960-1481(94)90109-0.

6. Yang, Y.; Wang, Q.; Xiu, D.; Zhao, Z.; Sun, Q. A building integrated solar collector: Allceramic solar collector. Energy and Buildings. 2013, 62, 15-17, https://doi.org/10.1016/j.enbuild.2013.03.002.

7. Sioshansi, F.-P. Distributed Generation and Its Implications for the Utility Industry. Elsevier, San Diego, CA 92101-4495, USA, 2014.

8. Amado, M.; Poggi, F. Solar Energy Integration in Urban Planning: GUUD Model. Energy Procedia. 2014, 50, 277-284, https://doi.org/10.1016/j.egypro.2014.06.034.

9. Erlat, G.-A.; Henry, B.-M.; Grovenor, C.-R.-M.; Briggs, A.-G.-D.; Chate,r R.-J.; Tsukahara, Y. Mechanism of Water Vapor Transport through PET/AlOxNy Gas Barrier Films. J Phys Chem B. 2004, 108, 883-890, https://doi.org/10.1021/jp036244y.

10. Wolf, M. Performance analysis of combined heating and photovoltaic power systems for residences. Energy Conversion. 1976, 16, 79-90, https://doi.org/10.1016/0013-7480(76)90018-8.

11. Florschuetz, L.-W. Extension of the Hottel-Whiller model to the analysis of combined photovoltaic/thermal flat plate collectors. Solar Energy. 1979, 22, 361-366, https://doi.org/10.1016/0038-092X(79)90190-7.

12. Kippelen, B.; Brédas, J.-L. Organic photovoltaics. Energy Environ. 2009, 2, 251-261, DOI: 10.1039/B812502N.

13. Brabec, C.-J. Organic photovoltaics: technology and market. Solar Energy Materials E Solar Cells. 2004, 83, 273-292, https://doi.org/10.1016/j.solmat.2004.02.030.

14. Su, Y.-W.; Lan, S.-C.; Wei, K.-H. Organic photovoltaics. Materials today. 2012, 15, 554-562, https://doi.org/10.1016/S13697021(13)70013-0.

15. Schüler, A.; Roecker, C.; Boudaden, J.; Oelhafen, P.; Scartezzini, J.-L. Potential of quarter wave interference stacks for colored thermal solar collectors. Solar Energy. 2005, 79, 122-130, https://doi.org/10.1016/j.solener.2004.12.008.

16. Mertin, S.; Hody-Le, C.-V.; Joly, M.; Mack, I.; Oelhafen, P.; Scartezzini, J.-L.; Schüler, A. Reactively sputtered coatings on architectural glazing for colored active solar thermal façades. Energy and Buildings. 2014, 68, 764-770, https://doi.org/10.1016/j.enbuild.2012.12.030.

17. Schueler, A.; Roecker, C.; Scartezzini, J.-L.; Boudaden, J.; Oelhafen, P. Designing thin film multilayer for colored glazed thermal collectors. EUROSUN. 2004, 2, 858-865, https://www.osti.gov/etdeweb/biblio/20672065.

18. BJ Power Co. Ltd. Solar Power System, Solar Modules, https://bjpower.en.ec21.com/; 2020 [accessed 06 December 2021].

19. SwssInso. SwissINSO-Technology, https://www.swissinso.com/technology; 2020 [accessed 06 December 2021].

20. Ahn, H.-S.; Gasonoo, A.; Jang, E.-J.; Kim, M.-H.; Lee, J.-H.; choi, Y. Transition Metal Oxide Multi-Layer Color Glass for Building Integrated Photovoltaic System. Institute of Korean Electrical and Electronics Engineers. 2019, 23, 1128-1133, https://doi.org/10.7471/ikeee.2019.23.4.1128.

21. Gasonoo, A.; Ahn, H.-S.; Kim, M.-H.; Lee, J.-H.; Choi, Y. Metal Oxide Multi-Layer Color Glass by Radio Frequency Magnetron Sputtering for Building Integrated Photovoltaic System. Institute of Korean Electrical and Electronics Engineers. 2018, 22, 1056-1061, https://doi.org/10.7471/ikeee.2018.22.4.1056. 
22. Gasonoo, A.; Ahn, H.-S.; Lim, S.-M.; Lee, J.-H.; Choi, Y. Color Glass by Layered Nitride Films for Building Integrated Photovoltaic (BIPV) System. Crystals. 2021, 11, 281-288, https://doi.org/10.3390/cryst11030281.

23. Rao, C.-N.-R. Transition Metal Oxides. Annu. Rev. Phys. Chem. 1989, 40, 291-326, https://doi.org/10.1146/annurev.pc.40.100189.001451.

24. DNF Co., Ltd. DNF BIPV Solar Color Glass, http://www.dnfsolution.com/sub02/sub03.html; 2021 [accessed 06 December 2021].

25. CQV Co., Ltd. Creation of Quality Value, http://cqv.co.kr/english/product01.htm; [accessed 06 December 2021].

26. Jeo, H.-J. Optical thin film practice. Hooks Hill. 2015, 1, 3. 